Manu Remanan, Rebbapragada Subba Rao, Shantanu Bhowmik, Lalit Varshney, Mathew Abraham and Karingamanna Jayanarayanan*

\title{
Hybrid nanocomposites based on poly aryl ether ketone, boron carbide and multi walled carbon nanotubes: evaluation of tensile, dynamic mechanical and thermal degradation properties
}

DOI 10.1515/epoly-2016-0162

Received June 16, 2016; accepted July 29, 2016; previously published online September 2, 2016

\begin{abstract}
In this study an attempt has been made to incorporate a radiation resistant filler like boron carbide $\left(\mathrm{B}_{4} \mathrm{C}\right)$ nanopowder along with multi walled carbon nanotubes (MWCNT) in a high performance polymer namely poly aryl ether ketone (PAEK) for potential applications in the nuclear industry. The dispersion of nanofillers in PAEK was established by scanning electron microscopy (SEM) and transmission electron microscopy (TEM). Infra red (IR) spectroscopy indicated the interaction between functionalized MWCNT (F-MWCNT) and PAEK. The optimum combination of $\mathrm{B}_{4} \mathrm{C}$ and F-MWCNT was obtained from the tensile property analysis. It was found from the dynamic mechanical analysis that the storage modulus of the composite at elevated temperature was enhanced by $\mathrm{B}_{4} \mathrm{C}$ inclusions. Mechanical damping factor spectra showed the shift of PAEK glass transition temperature to higher values due to the presence of $\mathrm{B}_{4} \mathrm{C}$ and F-MWCNT. Thermogravimetric analysis (TGA) presented the resistance offered by $\mathrm{B}_{4} \mathrm{C}$ to the degradation of PAEK especially at elevated temperatures.
\end{abstract}

*Corresponding author: Karingamanna Jayanarayanan, Department of Chemical Engineering and Materials Science, Amrita School of Engineering, Coimbatore, Amrita Vishwa Vidyapeetham, Amrita University, Tamil Nadu 641112, India, Tel.: +91-422-2685000, Fax:+91-422-2686274, e-mail: kj_narayanan@cb.amrita.edu; kjnarayanan@gmail.com

Manu Remanan and Rebbapragada Subba Rao: Department of Chemical Engineering and Materials Science, Amrita School of Engineering, Coimbatore, Amrita Vishwa Vidyapeetham, Amrita University, Tamil Nadu 641112, India

Shantanu Bhowmik: Department of Aerospace Engineering, Amrita School of Engineering, Coimbatore, Amrita Vishwa Vidyapeetham, Amrita University, Tamil Nadu 641112, India

Lalit Varshney: Radiation Technology Development Division, BARC, Mumbai 400085, India

Mathew Abraham: Gharda Chemicals Limited, Mumbai 421203 , India
Keywords: dynamic mechanical properties; morphology; polymer hybrid nanocomposites; tensile modulus; thermogravimetric analysis.

\section{Introduction}

High performance polymer composites are gaining importance and attempts are ongoing to utilize them as neutron shielding/sheathing materials (1). Polymer composites are being tried out for such applications owing to their lowdensity and capability to withstand degradation (2). There have been a few reports mentioning the use of radiation resistant fillers like boron carbon $\left(\mathrm{B}_{4} \mathrm{C}\right)$, boron nitride and tungsten powder in thermoset matrix $(3,4)$. Thermosets based composites are not generally preferred owing to their poor recyclability and difficulty in processing. Hence the selection of a suitable high performance polymer has to be restricted to thermoplastics. Yasin and Muhammad (5) studied the effect of boron carbide in high density polyethylene matrix and reported the various properties such as mechanical, thermal oxidative aging and swelling behavior in different solvents.

Among thermoplastic materials, poly ether ether ketone (PEEK) and poly aryl ether ketones (PAEK) are good candidates for nuclear applications. PEEK is a high temperature, tough, semi crystalline thermoplastic polymer having wide application in various areas like nuclear and aerospace industries (6). The improved strength, chemical resistance and crystallization occur due to the repetitive sequences of PEEK's molecular structure $(7,8)$. Compared to PEEK, PAEK has a higher glass transition temperature of $152^{\circ} \mathrm{C}$ and melting temperature of $372^{\circ} \mathrm{C}$ (9). PAEK polymer delivers extended high temperature performance in comparison with standard PEEK polymers while maintaining the same advantages such as toughness, strength and chemical resistance. Page et al. (8) studied PAEK, and found degradation tendencies during irradiation could be overcome by the addition of suitable fillers. 
$\mathrm{B}_{4} \mathrm{C}$ is an excellent choice to be used as a filler for radiation resistance due to its high cross section (706 barns) for absorption of neutrons (10). Apart from its high hardness it possesses low density and high chemical stability. It was found that the nano sized $\mathrm{B}_{4} \mathrm{C}$ particles in high density poly ethylene, increased the thermal neutron absorption ability but the mechanical property of the composite was reduced (11). The above mentioned characteristic makes $\mathrm{B}_{4} \mathrm{C}$ to be used as an excellent radiation shielding material.

It is widely agreed that the mechanical property of the thermoplastic composites decrease with $\mathrm{B}_{4} \mathrm{C}$ reinforcement percentage. Yasin and Muhammad (5) reported that as the $\mathrm{B}_{4} \mathrm{C}$ content increases, the mechanical properties of high density polyethylene-based composites are significantly reduced. It was also reported that higher concentration of $\mathrm{B}_{4} \mathrm{C}$ in epoxy led to poor adhesion and limited mechanical strength (3). By the addition of a suitable nano filler exhibiting good mechanical properties, along with $\mathrm{B}_{4} \mathrm{C}$, the above mentioned problem can be rectified. Carbon nanotubes (CNTs) are a potential candidate to be used as secondary nanofillers as they have high mechanical strength, high surface area, low density and importantly high electrical and thermal conductivities similar to that of copper $(12,13)$.

The incorporation of $\mathrm{B}_{4} \mathrm{C}$ tends to reduce the tensile strength of the polymer composite which dips even below that of the base polymer. The aim of this work is to study the synergistic effect of $\mathrm{B}_{4} \mathrm{C}$ nanopowder and multi walled carbon nanotubes (MWCNT) incorporated in PAEK in improving the static, dynamic mechanical and thermal degradation properties. The role of MWCNT is to compensate for the decline in static mechanical properties. In this study, PAEK is compounded with different weight percentage of $\mathrm{B}_{4} \mathrm{C}$ nanopowder and MWCNT. The extruded samples were injection moulded for various characterizations before neutron irradiation. The novelty of the present study is that no work has been carried out using $\mathrm{B}_{4} \mathrm{C}$ nanopowder and MWCNT simultaneously as fillers in PAEK polymer. The results from the current study can be used as a benchmark for comparing a variety of properties after subjecting the above hybrid composites to irradiation which will be the second phase of the study.

\section{Experimental work}

The base matrix material PAEK grade 1200P was obtained from Gharda Chemicals (Mumbai, India). The $\mathrm{B}_{4}$ C nanopowder of average particle size $30-60 \mathrm{~nm}$ was obtained from Reinste Ltd. (New Delhi, India). The MWCNT and $\mathrm{COOH}$ functionalized MWCNT (COOH-MWCNT) were obtained from United Nanotech Innovations (Bangalore, India). The average outer diameter of MWCNT is $20 \mathrm{~nm}$, the inside diameter is $16 \mathrm{~nm}$ and the average length is $20 \mu \mathrm{m}$ with purity greater than $97 \%$ which was produced with the chemical vapor deposition method. The silane coupling agent (3-glycidyloxypropyl)trimethoxysilane was procured from TCI (Tokyo, Japan).

The polymer based hybrid nanocomposites was prepared by a melt mixing technique using a co-rotating twin screw extruder (L/D ratio: 40:1). The temperature in the barrel of the twin screw extruder was maintained at $355^{\circ} \mathrm{C}-400^{\circ} \mathrm{C}$ from the feed zone to the die while the screw speed was kept at $300 \mathrm{rpm}$. The sample nomenclature for PAEK, an individual and hybrid nano composite from different weight percentages of $\mathrm{B}_{4} \mathrm{C}$, MWCNT and F-MWCNT is shown in Table 1. The granules which were pelletized

Table 1: Sample nomenclature of PAEK, individual and hybrid nanocomposites from $\mathrm{B}_{4} \mathrm{C}, \mathrm{MWCNT}, \mathrm{F}-\mathrm{MWCNT}$.

\begin{tabular}{|c|c|c|c|c|c|c|c|}
\hline Sl. no. & Samples & $\begin{array}{r}\text { PAEK } \\
(\%)\end{array}$ & $\begin{array}{r}\text { Untreated } B_{4} C \\
\text { nanopowder (\%) }\end{array}$ & $\begin{array}{r}\text { Treated } \mathrm{B}_{4} \mathrm{C} \\
\text { nanopowder (\%) }\end{array}$ & $\begin{array}{r}\text { MWCNT } \\
\text { (\%) }\end{array}$ & $\begin{array}{r}\text { F-MWCNT } \\
\text { (\%) }\end{array}$ & Code \\
\hline & Matrix & & & & & & \\
\hline \multirow[t]{2}{*}{1} & Polyaryl ether ketone & 100 & 0 & 0 & 0 & 0 & PAEK \\
\hline & Individual composites & & & & & & \\
\hline 2 & $0.75 \%$ (MWCNT) in PAEK & 99.25 & 0 & 0 & 0.75 & 0 & $0.75 \mathrm{C}$ \\
\hline 3 & $0.75 \%$ (F-MWCNT) in PAEK & 99.25 & 0 & 0 & 0 & 0.75 & $0.75 \mathrm{FC}$ \\
\hline \multirow[t]{2}{*}{4} & $0.75 \%$ (untreated $\mathrm{B}_{4} \mathrm{C}$ ) in PAEK & 99.25 & 0.75 & 0 & 0 & 0 & $0.75 \mathrm{~B}$ \\
\hline & Hybrid composites & & & & & & \\
\hline 5 & $0.75 \%$ (untreated $\mathrm{B}_{4} \mathrm{C}+\mathrm{F}-\mathrm{MWCNT}$ ) in PAEK & 99.25 & 0.375 & 0 & 0 & 0.375 & $0.75 \mathrm{BFC}$ \\
\hline 6 & $1.5 \%$ (untreated $\mathrm{B}_{4} \mathrm{C}+\mathrm{F}-\mathrm{MWCNT}$ ) in PAEK & 98.5 & 0.75 & 0 & 0 & 0.75 & $1.5 \mathrm{BFC}$ \\
\hline 7 & $2.25 \%$ (untreated $\mathrm{B}_{4} \mathrm{C}+\mathrm{F}-\mathrm{MWCNT}$ ) in PAEK & 97.75 & 1.125 & 0 & 0 & 1.125 & $2.25 \mathrm{BFC}$ \\
\hline 8 & $3 \%$ (untreated $\mathrm{B}_{4} \mathrm{C}+\mathrm{F}-\mathrm{MWCNT}$ ) in PAEK & 97 & 1.5 & 0 & 0 & 1.5 & $3 B F C$ \\
\hline 9 & $0.75 \%$ (untreated $\mathrm{B}_{4} \mathrm{C}+\mathrm{MWCNT}$ ) in PAEK & 99.25 & 0.375 & 0 & 0.375 & 0 & $0.75 B C$ \\
\hline 10 & $0.75 \%$ (treated $\mathrm{B}_{4} \mathrm{C}+\mathrm{F}-\mathrm{MWCNT}$ ) in PAEK & 99.25 & 0 & 0.375 & 0 & 0.375 & 0.75 TBFC \\
\hline
\end{tabular}


after extrusion was moulded using a BOY 22T automatic injection moulding machine into test samples. The temperature profile was maintained $390^{\circ} \mathrm{C}-410^{\circ} \mathrm{C}$ from the feed zone to the nozzle with a screw speed of $200 \mathrm{rpm}$.

\section{Characterization techniques}

To determine the size of the fillers and their dispersion scanning electron microscopy (SEM) and transmission electron microscopy (TEM) was made use of. For TEM analysis the samples were extracted by an ultramicrotome process. The Fourier transform infrared (FTIR) analysis was carried out using a NICOLET spectrometer in the range of $500-4000 \mathrm{~cm}^{-1}$.

The tensile properties of the polymer nanocomposites were studied using an INSTRON Universal testing machine at a crosshead speed of $1.25 \mathrm{~mm} / \mathrm{min}$ using the ASTM D-638 standard. For tensile properties, five samples were tested and average values are reported. The dynamic mechanical properties viz. storage and loss modulus ( $\mathrm{E}^{\prime}$ and $\mathrm{E}^{\prime \prime}$ ) and the damping factor $(\tan \delta)$ were evaluated in a dynamic mechanical analyzer (DMA) using a three-point bending mode in the range $30^{\circ} \mathrm{C}-350^{\circ} \mathrm{C}$ at $1 \mathrm{~Hz}$. For DMA, three samples were analyzed and consistent results were obtained. Thermogravimetric analysis (TGA) was carried out using a Universal V4.5A TA Instrument with heating rate of $10^{\circ} \mathrm{C} / \mathrm{min}-800^{\circ} \mathrm{C}$.

\section{Results and discussion}

\subsection{Morphological interpretation}

Figure $1 \mathrm{~A}-\mathrm{C}$ shows the SEM images of $\mathrm{B}_{4} \mathrm{C}$ nanopowder and MWCNTs. The micrograph clearly reveals the spherical structure of $\mathrm{B}_{4} \mathrm{C}$ nanopowder and the rod-like structure of MWCNT and F-MWCNT. As the nanofillers are in powder form, they are seen as agglomerated particles in the SEM morphology. TEM studies show the type of distribution of the nanofillers in the base matrix (14). Figure 2A-E shows the TEM micrographs explaining the distribution of individual and hybrid nano reinforcements such as $0.75 \mathrm{FC}$, 0.75B, 0.75BFC in PAEK. Figure 2A shows the dispersion of $0.75 \%$ F-MWCNT reinforcement. The TEM morphology depicts that the reinforcement F-MWCNT is in nanometer scale and suggests good dispersion in PAEK. It indicates the outer diameter and inner diameter of MWCNT as 20 and $16 \mathrm{~nm}$, respectively.

Figure $2 \mathrm{~B}$ reveals the morphology of $0.75 \% \mathrm{~B}_{4} \mathrm{C}$ nanofillers in the matrix. The TEM image shows that the $\mathrm{B}_{4} \mathrm{C}$ nanopowder is separated and dispersed throughout the matrix. The shape and particle size of the $\mathrm{B}_{4} \mathrm{C}$ nanopowder can be measured from the micrograph. It is found that the average particle size of $\mathrm{B}_{4} \mathrm{C}$ ranges from 30 to $60 \mathrm{~nm}$. The $\mathrm{B}_{4} \mathrm{C}$ nanoparticle is clearly visible by its shape and size. TEM images typically provide a small sampling for the


Figure 1: SEM images of (A) $B_{4} C$ nanopowder (B) MWCNT (C) F-MWCNT. 

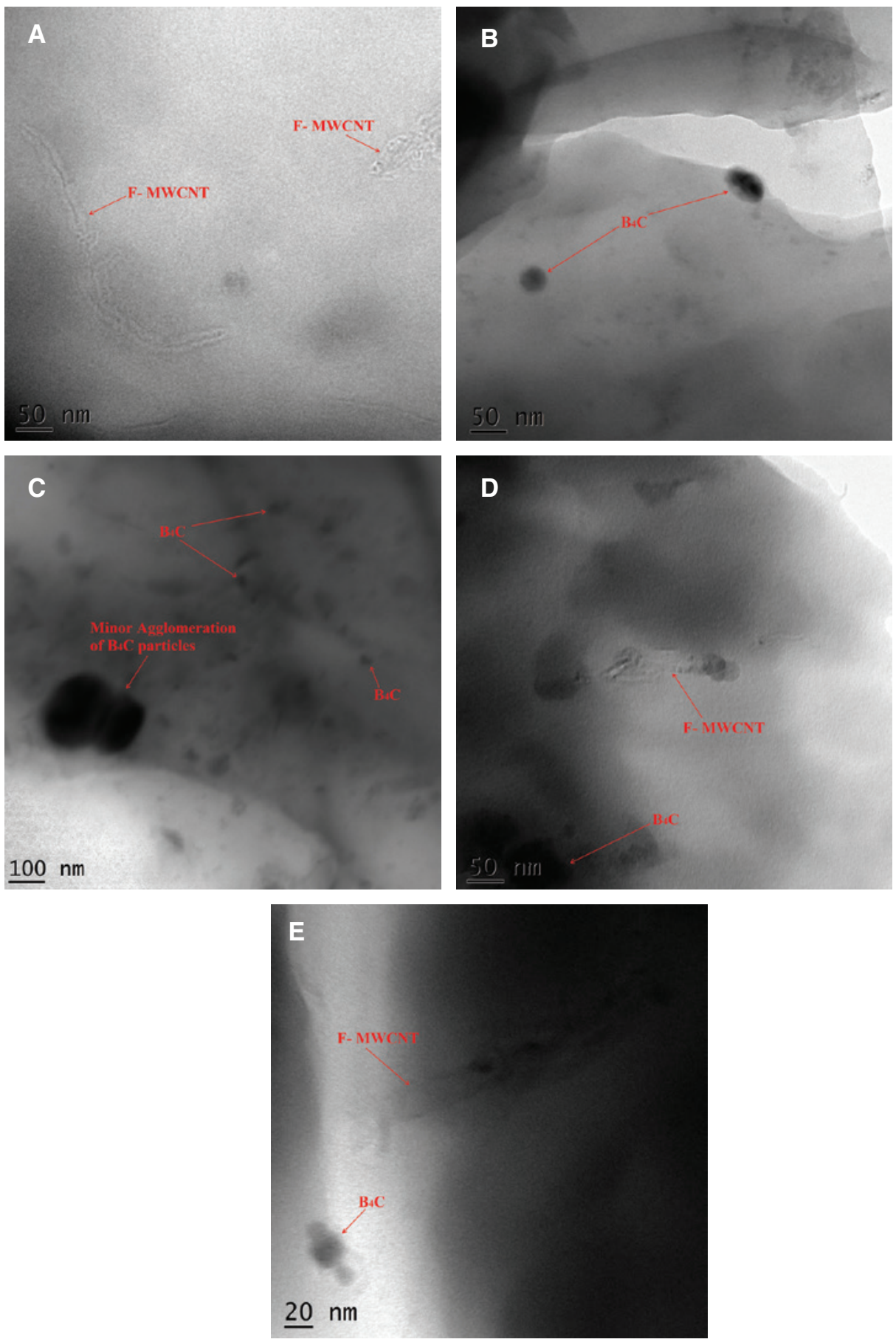

Figure 2: TEM image of (A) $0.75 F C$ (B) $0.75 B$ (C) $0.75 B$ at $100 \mathrm{~nm}$ scale (D) $0.75 B F C$ (E) higher magnified TEM image of $0.75 B F C$.

overall material. As the $\mathrm{B}_{4} \mathrm{C}$ particle size is of nanometer level, TEM is the best analysis method to know the information about the particle size. For large sampling for the overall material the TEM image of $100 \mathrm{~nm}$ scale is shown in Figure 2C.

Figure 2D depicts the TEM image of $0.75 \%$ of $\mathrm{B}_{4} \mathrm{C}$ and F-MWCNT nanofillers in the polymer PAEK. It is found that the outer diameter of F-MWCNT is same as that of the individual composite based on MWCNT. Similarly $\mathrm{B}_{4} \mathrm{C}$ particle size is also not varied by the hybrid inclusions. The higher magnified TEM morphology of 0.75BFC is shown in Figure 2E. From the morphological analysis, it can be inferred that the twin screw extrusion process enabled the nanofillers to distribute properly in PAEK. 


\subsection{Fourier transform infrared spectroscopy (FTIR)}

FTIR analysis can be employed to ensure whether the surface treatment or functionalization of filler is successfully carried out.

Figure 3A shows the FTIR spectra of PAEK, MWCNT, F-MWCNT, $\mathrm{B}_{4} \mathrm{C}$ and $\mathrm{TB}_{4} \mathrm{C}$. IR spectra of PAEK give the following details. The band at $1654 \mathrm{~cm}^{-1}$ shows the $\mathrm{C}=0$ stretching. The peak at $1585 \mathrm{~cm}^{-1}$ shows the benzene ring plane R-O-R vibration spectrum. At $1305 \mathrm{~cm}^{-1} \mathrm{R}$-CO-R stretching within the benzene ring plane vibration spectrum is seen. The $\mathrm{CH}$ bending of the aryl ketone structure within the benzene ring plane is at $1157 \mathrm{~cm}^{-1}$. R-CO-R of the symmetric stretching is obtained at $925 \mathrm{~cm}^{-1}(15)$. For $\mathrm{B}_{4} \mathrm{C}$ nanopowder FTIR shows two strong bands at $1581 \mathrm{~cm}^{-1}$ and at $1024 \mathrm{~cm}^{-1}$ which shows C-B-C and B-C stretching $(16,17)$. The broad form of $\mathrm{B}-\mathrm{C}, \mathrm{C}-\mathrm{C}$ and $\mathrm{BC}$ clusters in the vibration spectrum shows the presence of amorphous materials (17). The band at $3432 \mathrm{~cm}^{-1}$ and $1455 \mathrm{~cm}^{-1}$ indicate the $\mathrm{O}-\mathrm{H}$ and $\mathrm{B}-\mathrm{O}$ stretching, respectively $(17,18)$. The FTIR spectra for silane coupling agents indicates $\mathrm{C}-\mathrm{H}$ stretching at 2942 and 2843 $\mathrm{cm}^{-1}, \mathrm{CH}_{2}-\mathrm{O}-\mathrm{CH}_{2}$ stretching at $1193 \mathrm{~cm}^{-1}(19,20)$. The Si-O$\mathrm{CH}_{3}$ stretching is seen at $1088 \mathrm{~cm}^{-1}$ and epoxy ring at 1255 and $908 \mathrm{~cm}^{-1}(21,22)$. The $1156 \mathrm{~cm}^{-1}$ band indicates $\mathrm{Si}-\mathrm{OH}$ stretching which is absent in the FTIR spectra of untreated $\mathrm{B}_{4} \mathrm{C}$ nanopowder. B-C, Si-O-Si stretching occurs in the 1102 $\mathrm{cm}^{-1}$ band. $\mathrm{CH}-\mathrm{CH}_{2}$ stretching intensity reduced at 2922 and $2656 \mathrm{~cm}^{-1}$ after silane treatment. C-B-C stretching occurs at the $1648 \mathrm{~cm}^{-1}$ band. Bi-O-Si stretching occurs at bands $1410,926,851 \mathrm{~cm}^{-1}$ (3). These data clearly suggests that silane functional group is attached to $\mathrm{B}_{4} \mathrm{C}$ nanopowder.
In the FTIR spectrum of MWCNT, the O-H stretch took place at $3400 \mathrm{~cm}^{-1}$. The peak at $1630 \mathrm{~cm}^{-1}$ refers the backbone stretching of carbon nanotube. The carboxyl group (COOH) stretching occurs at $1720 \mathrm{~cm}^{-1}$ band during - $\mathrm{COOH}$ modification of MWCNT (23). At $1720 \mathrm{~cm}^{-1}$ in MWCNT the carboxyl group stretching is missing. But in F-MWCNT FTIR spectra the carboxyl group peak is at $1720 \mathrm{~cm}^{-1}$ band. The broad absorption band at $3432 \mathrm{~cm}^{-1}$ in F-MWCNT shows that the oscillation of carboxyl group. In the F-MWCNT the vibration at $3432 \mathrm{~cm}^{-1}$ suggests the $\mathrm{O}-\mathrm{H}$ stretch from carboxyl group indicating - $\mathrm{COOH}$ functional groups are clearly attached on nanotubes (24).

When pristine MWCNT is introduced, the peak at $1654 \mathrm{~cm}^{-1}$ in PAEK slightly shifted to $1652 \mathrm{~cm}^{-1}$ which shows that it has very little interaction with PAEK. A good shift is observed when functionalized MWCNT (F-MWCNT) was incorporated in the PAEK. The band shifted to $1644 \mathrm{~cm}^{-1}$ manifesting good interaction between the reinforcement and the matrix. This proves that the- $\mathrm{COOH}$ modification provides stronger interfacial interaction between the polymer matrix and the CNT. It was reported by Roy (25) that hydrogen bonding will be formed between - $\mathrm{COOH}$ and ketone groups. Figure 3B shows the scheme of this interaction.

\subsection{Tensile properties}

The tensile properties of PAEK with individual and hybrid loadings of nanofillers such as treated and untreated $\mathrm{B}_{4} \mathrm{C}$ nanopowder, MWCNT and F-MWCNT are shown in Table 2. The stress-strain curves of PAEK and different composites are delineated in Figure 4. The tensile strength and modulus


Figure 3: (A) FTIR spectra of PAEK, MWCNT, F-MWCNT, $\mathrm{B}_{4} \mathrm{C}$ and $\mathrm{TB}_{4} \mathrm{C}$. (B) Schematic representation of the interaction between PAEK and $\mathrm{COOH}$ modified MWCNT. 
Table 2: Tensile properties of PAEK and nanocomposites.

\begin{tabular}{|c|c|c|c|c|}
\hline Sl. no. & Samples & $\begin{array}{r}\text { Tensile strength } \\
(\mathrm{MPa})\end{array}$ & $\begin{array}{r}\text { Tensile modulus } \\
(\mathrm{MPa})\end{array}$ & $\begin{array}{r}\text { Strain at break } \\
(\%)\end{array}$ \\
\hline & Matrix & & & \\
\hline \multirow[t]{2}{*}{1} & PAEK & $100 \pm 0.2$ & $2442 \pm 14.4$ & $19.6 \pm 0.9$ \\
\hline & Individual co & & & \\
\hline 2 & $0.75 B$ & $97.7 \pm 0.4$ & $2989 \pm 10.3$ & $5.6 \pm 0.7$ \\
\hline 3 & $0.75 \mathrm{C}$ & $102.6 \pm 0.3$ & $2503 \pm 21.4$ & $25 \pm 1.5$ \\
\hline \multirow[t]{2}{*}{4} & $0.75 \mathrm{FC}$ & $108 \pm 0.6$ & $2559 \pm 12.8$ & $25 \pm 1.8$ \\
\hline & Hybrid comp & & & \\
\hline 5 & $0.75 \mathrm{BFC}$ & $101 \pm 0.3$ & $3011 \pm 25.7$ & $23.5 \pm 1.0$ \\
\hline 6 & $1.5 \mathrm{BFC}$ & $92 \pm 0.3$ & $3021 \pm 23.5$ & $4.5 \pm 0.3$ \\
\hline 7 & $2.25 \mathrm{BFC}$ & $83.5 \pm 0.8$ & $3034 \pm 20.6$ & $3.7 \pm 0.2$ \\
\hline 8 & $3 B F C$ & $79 \pm 0.4$ & $3059 \pm 27.8$ & $3.5 \pm 0.2$ \\
\hline 9 & $0.75 B C$ & $95.2 \pm 0.6$ & $3068 \pm 26.6$ & $4.5 \pm 0.4$ \\
\hline 10 & $0.75 \mathrm{TBFC}$ & $104.8 \pm 0.4$ & $3262 \pm 37.5$ & $14 \pm 0.9$ \\
\hline
\end{tabular}



Figure 4: Stress strain curves of PAEK and nanocomposites.

of neat PAEK is $100 \mathrm{MPa}$ and $2442 \mathrm{MPa}$, respectively. In the individual effect it is observed that the tensile strength of 0.75B reduced to $97.7 \mathrm{MPa}$, but the modulus enhanced to $2989 \mathrm{MPa}$ which is evident from the increase in the slope of the initial linear portion of the stress-strain curve. Even a minor loading of $\mathrm{B}_{4} \mathrm{C}(0.75 \%)$ made the composite brittle as evident from the low elongation at break of $5.6 \%$. The earlier studies (3) exhibited similar reduction in the mechanical properties of the composites based on HDPE. It is observed that the tensile strength and modulus of $0.75 \mathrm{C}$ is $102.6 \mathrm{MPa}$ and $2503 \mathrm{MPa}$, respectively, which shows that there is no significant improvement in the tensile properties compared to PAEK. A remarkable increase in tensile strength is obtained in $0.75 \mathrm{FC}$. It is found that the tensile strength is $108 \mathrm{MPa}$ and elongation at break is $25 \%$ which made the composite to exhibit a ductile failure. This reveals that the functionalization of MWCNT improved the tensile properties.

The tensile properties of hybrid composites, 1.5BFC, 2.25BFC and 3BFC are indicated in Table 2. There is remarkable reduction in the tensile properties. It is clearly seen from the graph that as the weight percentage of the hybrid nanofillers in the polymer increased beyond $0.75 \%$, the tensile strength reduced. In order to analyze the effect of treatment and functionalization of nanofillers $0.375 \mathrm{wt} \%$ each of $\mathrm{B}_{4} \mathrm{C}$ and MWCNT were made use of. In $0.75 \mathrm{BC}$ the tensile strength and elongation at the break reduced to $95.2 \mathrm{MPa}$ and $4.5 \%$, respectively. The composite $0.75 \mathrm{BFC}$ indicated the tensile strength and modulus value of $101 \mathrm{MPa}$ and $3011 \mathrm{MPa}$, respectively. However the elongation at the break increased to $23.5 \%$. Among the hybrid composites 0.75TBFC shows good tensile properties. The tensile strength and modulus of 0.75TBFC was obtained as 104.8 MPa and $3262 \mathrm{MPa}$, respectively, with $14 \%$ elongation at the break. This clearly reveals that both treated and untreated $\mathrm{B}_{4} \mathrm{C}$ in hybrid composites have comparable tensile modulus at $0.75 \%$ loading of nanofillers. During extrusion of the 0.75TBFC composite there was a color change in the composite as the strands emerged from 
the die. This may be due to entrapment of volatiles generated during silane surface treatment which are difficult to remove. As the properties of $0.75 \mathrm{TBFC}$ and $0.75 \mathrm{BFC}$ are comparable it was decided to carry out the experiments using untreated $\mathrm{B}_{4} \mathrm{C}$ and F-MWCNT.

In the tensile strength of the composite, the properties and structure of the filler matrix interface play an important role. Boron carbide is a hard ceramic particle. By the incorporation of boron carbide, the composite tensile strength reduces and becomes brittle as the reinforcement percentages increases. This is due to the lack of proper bonding between boron carbide and base matrix PAEK. The advantage by the inclusion of boron carbide in the matrix is that the modulus of the composite increased. In the present work the strength of the hybrid composite increased at room temperature when silane treatment was carried out on boron carbide.

\subsection{Dynamic mechanical analysis (DMA)}

To study the thermo mechanical behavior of polymer composites at elevated temperature, DMA is considered to be a powerful tool (26).
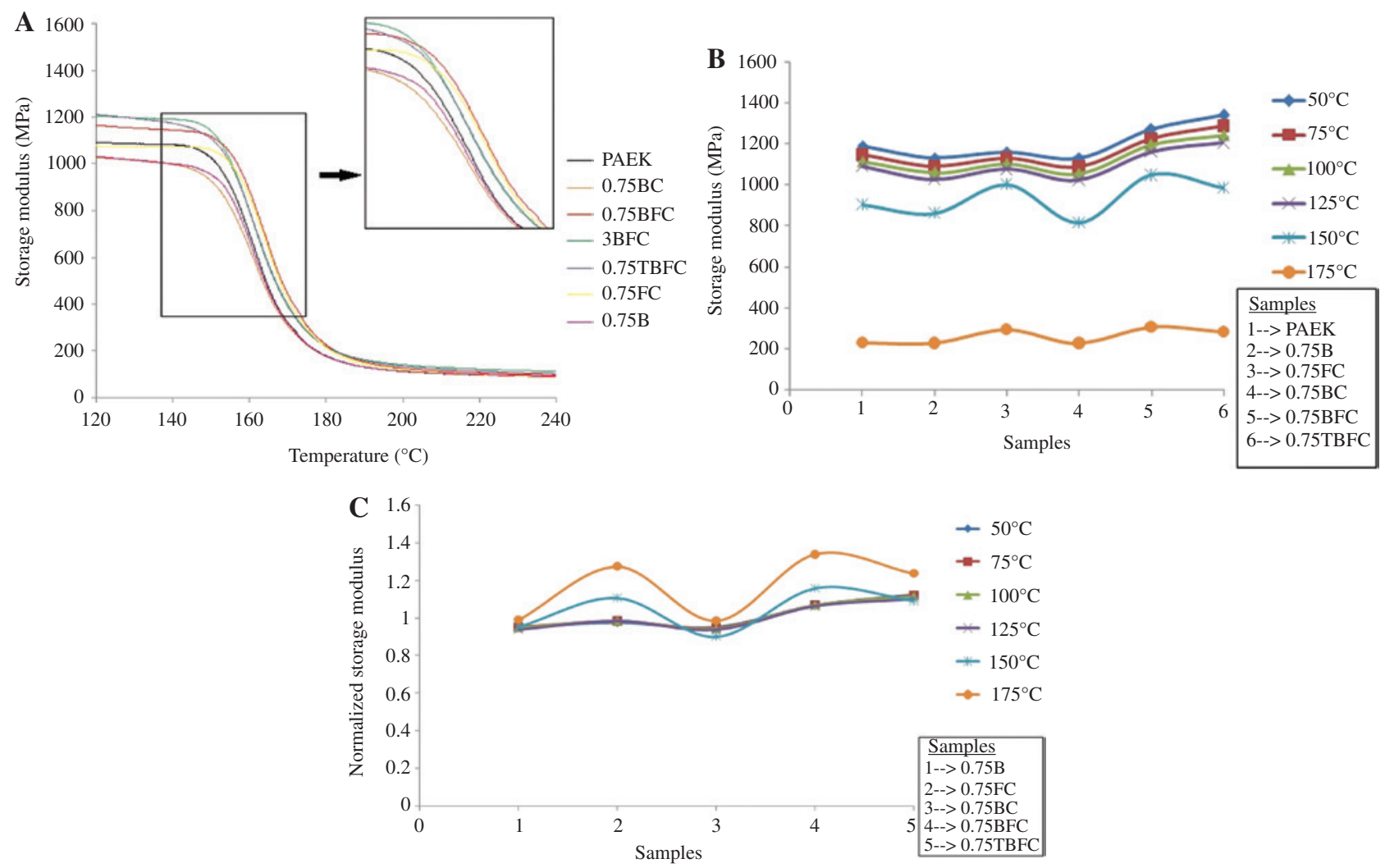

Figure 5: (A) Variation of storage modulus with temperature for PAEK and nanocomposites. (B) Variation of storage modulus of PAEK and nanocomposites at $50^{\circ} \mathrm{C}, 75^{\circ} \mathrm{C}, 100^{\circ} \mathrm{C}, 125^{\circ} \mathrm{C}, 150^{\circ} \mathrm{C}$, and $175^{\circ} \mathrm{C}$. (C) Variation of normalized storage modulus of individual and hybrid nanocomposites at $50^{\circ} \mathrm{C}, 75^{\circ} \mathrm{C}, 100^{\circ} \mathrm{C}, 125^{\circ} \mathrm{C}, 150^{\circ} \mathrm{C}, 175^{\circ} \mathrm{C}$.

\subsubsection{Storage modulus $\left(E^{\prime}\right)$}

Storage modulus $\left(E^{\prime}\right)$ is regarded as the ability of the material to store energy during deformation and it is an indicator of the elastic characteristics of viscoelastic materials. Figure $5 \mathrm{~A}$ represents the variation of $\mathrm{E}^{\prime}$ with the temperature of PAEK, individual and hybrid nano composites. In comparison with PAEK it is found that there is an enhancement in the storage modulus for 3BFC, 0.75TBFC and $0.75 \mathrm{BFC}$. The individual nano composite $0.75 \mathrm{FC}$ indicates almost the same storage modulus compared to the base matrix. There is a decrease in the storage modulus $\left(\mathrm{E}^{\prime}\right)$ for $0.75 \mathrm{BC}$ and $0.75 \mathrm{~B}$. This can be attributed to the poor interaction between hard $\mathrm{B}_{4} \mathrm{C}$ particles in the matrix. The variation of the storage modulus at different temperatures is depicted in Figure 5B. It is clear from the plot that at room temperature the effect of $\mathrm{B}_{4} \mathrm{C}$ treatment shows good results. The storage modulus of $0.75 \mathrm{TBFC}$ is found to be highest amongst all the composites with a value of $1350 \mathrm{MPa}$. The effect of silane treatment was, however, found to be less influential in maintaining the storage modulus at elevated temperature of $150^{\circ} \mathrm{C}$. At this temperature the highest modulus was obtained for 0.75BFC, $1050 \mathrm{MPa}$ in comparison with $950 \mathrm{MPa}$ for 0.75TBFC. This

$\rightarrow 50^{\circ} \mathrm{C}$

$-100^{\circ} \mathrm{C}$

$-125^{\circ} \mathrm{C}$

$150^{\circ} \mathrm{C}$

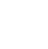

\footnotetext{
storage modulus of PAEK and
of individual and hybrid nano
} 
indicates that the acid modification of MWCNT is contributing much more than silane treatment of $\mathrm{B}_{4} \mathrm{C}$ towards the stiffness at higher temperature.

The normalized storage modulus is defined as the ratio of the storage modulus of the composite to the storage modulus of the matrix at the same temperature (27). The influence of individual and hybrid reinforcement in the base matrix PAEK at different temperatures are studied and illustrated in Figure 5C. It is evident from the figure the individual composite $0.75 \mathrm{FC}$ shows an increase in the normalized storage modulus in the entire temperature range. In the case of the hybrid effect of loadings, at room temperature, 0.75TBFC shows an increase in the normalized storage modulus compared to $0.75 \mathrm{BFC}$. As the temperature increases, $0.75 \mathrm{BFC}$ exhibits higher normalized storage modulus compared to 0.75TBFC. This explains that at higher temperature the 0.75TBFC composite is not stable due to the decomposition of silanes at higher temperatures. The higher normalized storage modulus value for $0.75 \mathrm{BFC}$ further indicates the hindrance offered by the nanofillers to the movement of polymer molecules at elevated temperatures of $150^{\circ} \mathrm{C}$ and $175^{\circ} \mathrm{C}$. The contribution of functionalization of MWCNT in the $0.75 \mathrm{BFC}$ plays an important role for the stiffness of the composite at higher temperature which is evident from the graph. From the trace of the sample 2 and 4, it is seen that functionalization of MWCNT contributes greatly to maintaining higher stiffness at $175^{\circ} \mathrm{C}$.

\subsubsection{Loss modulus ( $\left.E^{\prime \prime}\right)$}

Loss modulus ( $\mathrm{E}^{\prime \prime}$ ) or dynamic loss modulus represents the viscous response and tendency to dissipate energy as heat (28). The variation of loss modulus with temperature for individual and hybrid reinforcement in PAEK is shown in Figure 6. Amongst the individual nano composites, $0.75 \mathrm{FC}$ exhibits higher energy dissipation compared to $0.75 \mathrm{~B}$. It is observed from the graph that $0.75 \mathrm{BFC}$ manifest a higher value of loss modulus compared to individual and other hybrid composites. Thus $0.75 \mathrm{BFC}$ dissipates maximum energy as heat and indicate high viscous response. In the case of 0.75TBFC composite, viscous dissipation was poor as compared to $0.75 \mathrm{BFC}$. It was reported that high loss modulus indicates the restriction on the segmental mobility of the polymer chain (29).

\subsubsection{Damping factor $(\tan \delta)$}

The damping factor or tan $\delta$ regarded as a dimensionless number is defined as the ratio of loss modulus ( $\left.\mathrm{E}^{\prime \prime}\right)$ to

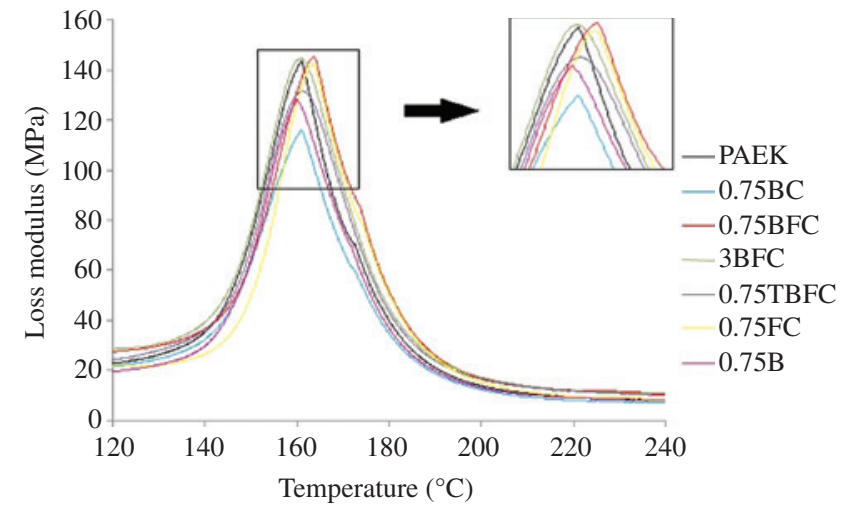

Figure 6: Variation of loss modulus of PAEK and nanocomposites.

storage modulus $\left(E^{\prime}\right)$. Figure 7 shows the variation of the damping factor with the temperature for different individual and hybrid reinforcement in PAEK. If the matrix and reinforcement shows good interfacial bonding, it results in the reduction in the peak of the $\tan \delta$ curve. The $\mathrm{T}_{\mathrm{g}}$ of the composite plays an important role in the $\tan \delta$ analysis. The positive shift in the $\mathrm{T}_{\mathrm{g}}$ value shows good mechanical stability of the composite. At a particular frequency the broadening of $\tan \delta$ curve indicates the hindrance to the slippage of the polymer molecules (30).

Compared to base matrix all individual and hybrid composites indicate a reduction in the $\tan \delta$ peak value. In the individual effect it is observed that the damping factor is less for 0.75B compared to 0.75FC. In the hybrid effect it is found that the damping factor of $0.75 \mathrm{TBFC}$ is marginally lower than that of $0.75 \mathrm{BFC}$ and other hybrid composites. This indicates high elasticity and noise absorption of the $0.75 \mathrm{TBFC}$ at temperatures below $150^{\circ} \mathrm{C}$.

Due to silane treatment better bonding between boron carbide and PAEK takes place in 0.75TBFC which causes

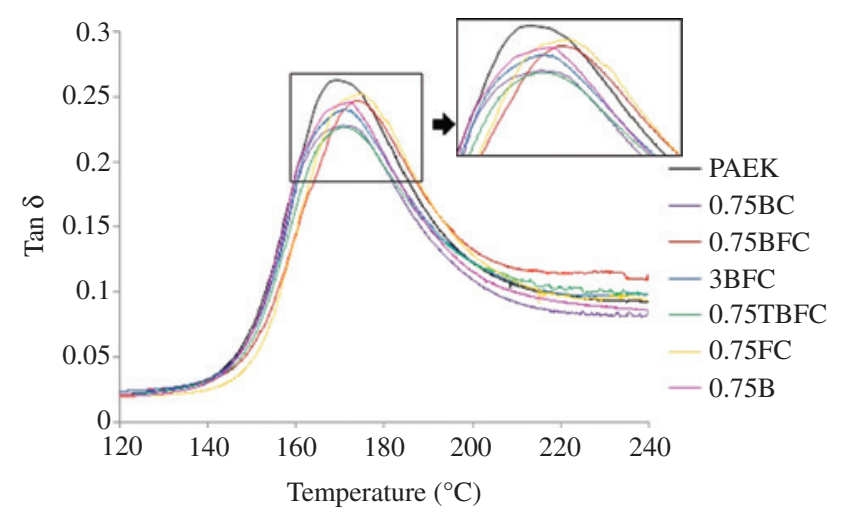

Figure 7: Variation of mechanical damping factor of PAEK and nanocomposites. 
Table 3: Non isothermal decomposition characteristics of PAEK and nanocomposites.

\begin{tabular}{|c|c|c|c|c|c|c|}
\hline Sl. no. & Samples & $\mathrm{T}_{\text {onset }}\left({ }^{\circ} \mathrm{C}\right)$ & $\mathrm{T}_{\max }\left({ }^{\circ} \mathrm{C}\right)$ & $\begin{array}{r}\text { Temperature } \\
\text { at } \mathrm{T}_{0.1}\left({ }^{\circ} \mathrm{C}\right)\end{array}$ & $\begin{array}{r}\text { Temperature } \\
\text { at } \mathrm{T}_{0.4}\left({ }^{\circ} \mathrm{C}\right)\end{array}$ & $\begin{array}{r}\text { Yield at } \\
800^{\circ} \mathrm{C}(\%) \\
\end{array}$ \\
\hline & Matrix & & & & & \\
\hline \multirow[t]{2}{*}{1} & PAEK & 530.4 & 562.6 & 552 & 634 & 52.7 \\
\hline & Individual co & & & & & \\
\hline 2 & $0.75 B$ & 554.4 & 571.5 & 565 & 743 & 58.7 \\
\hline \multirow[t]{2}{*}{3} & $0.75 \mathrm{FC}$ & 547.6 & 567.4 & 559 & 671 & 55.9 \\
\hline & Hybrid comp & & & & & \\
\hline 4 & 0.75 TBFC & 540.5 & 564.2 & 555 & 679 & 56.2 \\
\hline 5 & $0.75 \mathrm{BFC}$ & 554.9 & 572.1 & 565 & 734 & 58.5 \\
\hline
\end{tabular}

the lowering of $\tan \delta$ peak value. But positive right side shift of the peak (corresponding to $\mathrm{T}_{\mathrm{g}}$ ) was not seen compared to $0.75 \mathrm{BFC}$. This indicates that the $0.75 \mathrm{TBFC}$ composite becomes flexible at higher temperatures like $150^{\circ} \mathrm{C}$ and $175^{\circ} \mathrm{C}$. Elevation of $\mathrm{T}_{\mathrm{g}}$ is taken as a measure of interfacial interaction. In the case of $0.75 \mathrm{BFC}$ broadening of the peak is seen which can be attributed to restricted relaxation (27). The composite with higher value of $\mathrm{T}_{\mathrm{g}}$ indicates that the nanofillers impede the mobility of polymer chains. For the hybrid effect of reinforcement, it is found from the graph that the $0.75 \mathrm{BFC}$ shows maximum positive $\mathrm{T}_{\mathrm{g}}$ shift compared to other composites and $5^{\circ} \mathrm{C}$ to base matrix PAEK. So $0.75 \mathrm{BFC}$ is stable and rigid compared to other composites. It shows a good interaction between the reinforcement and matrix which require higher temperature to initiate the slippage of coiled polymer chains past the nanofillers. The peak value obtained is lower for 3BFC composite due to higher reinforcement percentage of nanofillers but they are comparatively ineffective in reinforcing the polymer as there is no evidence of positive shift of the relaxation peak.

\subsection{Thermogravimetric analysis (TGA)}

The loading of fillers in the polymer can improve the resistivity and their interaction helps in delaying the degradation of the polymer composite (31). Thermal decomposition studies of polymer composites used in radiation resistant application is of paramount importance as the service temperature is expected to be high. TGA analysis is expected to throw light on the influence of $\mathrm{B}_{4} \mathrm{C}$ and MWCNT on the decomposition of PAEK. The thermal degradation parameters of PAEK, 0.75B, 0.75FC, $0.75 \mathrm{TBFC}$ and $0.75 \mathrm{BFC}$ are presented in Table $3 . \mathrm{T}_{\text {onset }}$ represents the temperature at which the degradation is initiated and $\mathrm{T}_{\max }$ the temperature at which the weight loss is maximum. $\mathrm{T}_{0.1}$ and $\mathrm{T}_{0.4}$ indicate the temperature at $10 \%$ and $40 \%$ weight loss, respectively. The yield at $800^{\circ} \mathrm{C}$ is also reported.

The loss of weight with temperature for the various samples is delineated in Figure 8A. It is clearly seen that all the individual and hybrid composites decomposed in a single step. It is observed from Table 3 and Figure 8A that among all the composites, $0.75 \mathrm{~B}$ and $0.75 \mathrm{BFC}$ shows useful results. $\mathrm{T}_{\text {onset }}$ of both the samples are shifted to $554^{\circ} \mathrm{C}$ from $530^{\circ} \mathrm{C}$ of PAEK. In 0.75TBFC the onset degradation temperature is $540.5^{\circ} \mathrm{C}$. It can be inferred that the presence of untreated $\mathrm{B}_{4} \mathrm{C}$ helps much more than the treated counterpart in delaying the degradation. The
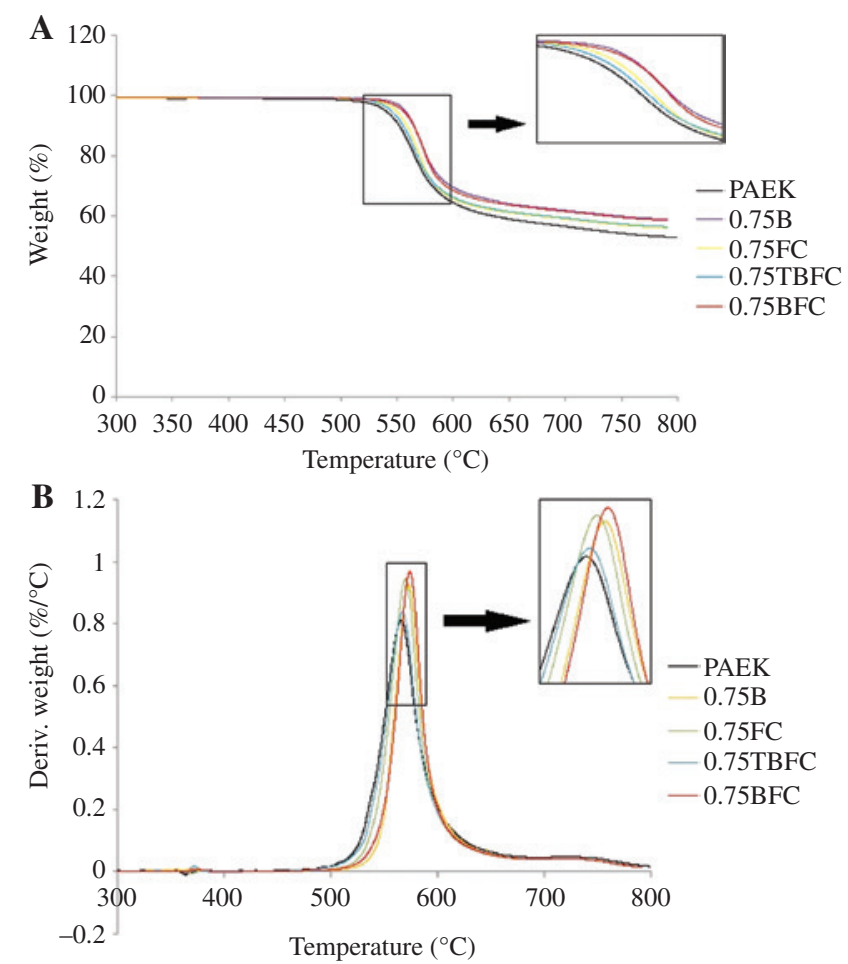

Figure 8: (A) Dynamic TG profiles of PAEK and nanocomposites. (B) The derivative thermogram of PAEK and nanocomposites. 
major finding is that the temperature at $40 \%$ weight loss for $0.75 \mathrm{~B}$ and $0.75 \mathrm{BFC}$ is almost $100^{\circ} \mathrm{C}$ higher than that of PAEK. At $800^{\circ} \mathrm{C}$ it is found that around $58 \%$ material remains for both $0.75 \mathrm{~B}$ and $0.75 \mathrm{BFCwhich}$ is $6 \%$ more than that of neat PAEK.

Figure $8 \mathrm{~B}$ shows the derivative thermogravimetric curves. It gives information on the temperature at which maximum weight loss happens (32). From the plot it is observed that $0.75 \mathrm{~B}$ and $0.75 \mathrm{BFC}$ show good results as they indicate a positive right side shift for the peak of the curve. It is found that for both the samples around $10^{\circ} \mathrm{C}$ a positive right side shift has occurred compared to PAEK. This shift is only $2^{\circ} \mathrm{C}$ for TBFC suggesting the inability of treated $\mathrm{B}_{4} \mathrm{C}$ in delaying the degradation.

\section{Conclusion}

The incorporation of $\mathrm{B}_{4} \mathrm{C}$ and MWCNT nanofillers in the high temperature and high performance polymer (PAEK) has been successfully carried out using a twin screw extruder followed by injection moulding. The TEM images indicated that the twin screw extrusion process enabled the nanofillers to distribute properly in the base matrix. It is observed from the tensile property analysis that the tensile strength of the composite reduced as the $\mathrm{B}_{4} \mathrm{C}$ content in the matrix increased. However $\mathrm{B}_{4} \mathrm{C}$ contributes to the increase in the tensile modulus of the composite. The modulus of $0.75 \mathrm{BFC}$ is found to be $3011 \mathrm{MPa}$ which is $23 \%$ more than that of base matrix. Dynamic mechanical properties such as storage modulus ( $\left.\mathrm{E}^{\prime}\right)$, loss modulus ( $\left.\mathrm{E}^{\prime \prime}\right)$ and damping factor were investigated. The effect of silane treatment was observed to be less significant to maintain the storage modulus at elevated temperatures of $150^{\circ} \mathrm{C}$ and $175^{\circ} \mathrm{C}$. The functionalization of MWCNT contributed much more than the silane treatment of $\mathrm{B}_{4} \mathrm{C}$ towards the increase in storage modulus. The TGA indicated the resistance offered by untreated $\mathrm{B}_{4} \mathrm{C}$ to the degradation of PAEK. The temperature at $40 \%$ wt. loss for $0.75 \mathrm{~B}$ and $0.75 \mathrm{BFC}$ was almost $100^{\circ} \mathrm{C}$ higher than that of PAEK. The onset and maximum temperature for degradation was found to be more for $0.75 \mathrm{~B}$ and $0.75 \mathrm{BFC}$ and it was found to be in the range of $554^{\circ} \mathrm{C}$ and $572^{\circ} \mathrm{C}$, respectively, for both the samples.

Acknowledgment: The authors greatly acknowledge the financial support from Board of Research in Nuclear Science (BRNS) (Grant/Award Number: '35/14/49/2014BRNS/10011'), Department of Atomic Energy (DAE), India to carry out this work.

\section{References}

1. Comby B. Environmentalists for nuclear energy. TNR ed; Paris; 2006. $350 \mathrm{p}$.

2. Kharita MH, Yousef S, AlNassar M. Review on the addition of boron compounds to radiation shielding concrete. Prog Nucl Energy. 2011;53:207-11.

3. Rodrigues DD, Broughton JG. Silane surface modification of boron carbide in epoxy composites. Int J Adhes Adhes. 2013;46:62-73.

4. Chang L, Zhang Y, Liu Y, Fang J, Luan W, Yang X, Zhang W. Preparation and characterization of tungsten/epoxy composites for $\gamma$-rays radiation shielding. Nucl Instr Meth Phys Res. 2015;356-7:88-93.

5. Yasin T, Muhammad NK. High density polyethylene/boron carbide composites for neutron shielding. e-Polymers. 2008;059:1618-7229.

6. VICTREX PEEK. A Guide to Grades for Injection Moulding UK2/0785. Wilmington, USA: ICI Americas Inc., 1986.

7. Sperling LH. Introduction to physical polymer science. 2nd ed. New York: John Wiley \& Sons; 1992. 261-263 pp.

8. Page JYS, Bonin HW, Bui VT. Neutron and Gamma Radiation Effects on the viscoelastic behaviour of poly(aryl ether ether ketone). M. Eng. Thesis, Royal Military College of Canada; 1997.

9. Gharda Chemicals. G-PAEK Ultra High Performance Polymer, Revision 2010.

10. Glasstone S, Sesonske A. Nuclear reactor engineering. 3rd ed. Florida: Florida: Krieger Publishing Company; 1981.

11. Uhm YR, Kim J, Jung J, Rhee CK. Fabrications of PVA coated nano- $\mathrm{B}_{4} \mathrm{C}$ reinforced HDPE composites. Mod Phys Lett $\mathrm{B}$. 2009;23:3931-6.

12. Ebbesen TW, Lezec HJ, Hiura H, Bennett JW, Ghaemi HF, Thio T. Electrical conductivity of individual carbon nanotubes. Nature. 1996;382:54-6.

13. Ajeesh G, Bhowmik S, Venugopal S, Varshney L, Baluch A, Park Y, Gilsang S, Kim CG. Influence of chemically and plasmafunctionalized carbon nanotubes on high-performance polymeric nanocomposites. High Perform Polym. 2015;28:570-80.

14. Gojny FH, Wichmann MHG, Fiedler WB, Schulte K. Influence of different carbon nanotubes on the mechanical properties of epoxy matrix composites - a comparative study. Compos Sci Technol. 2005;65:2300-13.

15. Polyaryletherketone copolymers containing cyano group and preparation method for polyaryletherketone copolymers. Publication number: CN 102492132 A, Application number CN 201110408163, 2012.

16. Ghosh D, Subhash G, Lee CH, Yap YK. Strain-induced formation of carbon and boron clusters in boron carbide during dynamic indentation. Appl Phys Lett. 2007;91(6):061910.

17. Rodríguez MG, Kharissova OV, Ortiz-Méndez U. Formation of boron carbide nano fibers and nano belts from heated by microwave. Rev Adv Mater Sci. 2004;7(1):55-60.

18. Mondal S, Banthia AK. Low-temperature synthetic route for boron carbide. J Eur Ceram Soc. 2005;25(2):287-91.

19. Bertelsen CM, Boerio FJ. Linking mechanical properties of silanes in chemical structure: ananalytical study of $\gamma$-GPS solutions and films. Prog Org Coat. 2001;41(4):239-46.

20. Johnsen BB, Olafsen K, Stori A. Reflection-absorption FT-IR studies of the specific interaction of amines and an epoxy 
adhesive with GPS treated aluminium surfaces. Int J Adhes. 2003;23(2):155-63.

21. Parke AA, MacLachlan J. The Relationship between silane hydrolysis and polymer adhesion to glass as studied by ${ }^{13} \mathrm{C}$ solid state NMR. In silanes and other coupling agents, Vol. 2, Mittal KL, editor. The Netherlands: VSP BV; 2000. 27-40 pp.

22. Xue G, Koenig JL, Ishida H, Wheeler DD. Chemical reactions of an epoxy-functional silane in aqueous solutions. Rubber Chem Technol. 1991;64(2):162-71.

23. Ahmed DS, Haider AJ, Mohammad MR. Comparison of functionalization of MWCNTs treated by oil olive and nitric acid and their characterization. Energy Procedia. 2013;36:1111-8.

24. Abuilaiwi FA, Laoui T, Al-Harthi M, Atieh MA. Modification and functionalization of multiwalled carbon nanotube via fischer esterification. Arab J Sci Eng. 2010;35:1.

25. Roy S, Sahoo NG, Cheng HK, Das CK, Chan SH, Li L. Molecular interaction and properties of poly(ether ether ketone)/ liquid crystalline polymer blends incorporated with functionalized carbon nanotubes. J Nanosci Nanotechnol. 2011;11:10408-16.

26. Jawaid M, Khalil HPSA, Hassana A, Dungani R, Hadiyane A. Effect of jute fibre loading on tensile and dynamic mechanical properties of oil palm epoxy composites. Compos Part B Eng. 2013;45:619-24.

27. Jayanarayanan K, Thomas S, Joseph K. Morphology, static and dynamic mechanical properties of in situ microfibrillar composites based on polypropylene/poly(ethylene terephthalate) blends. Composites: Part A. 2008;39:164-75.

28. Zhang Z, Wang P, Wu J. Dynamic mechanical properties of EVA polymer modified cement paste at early age. Phys Procedia. 2012;25:305-10.

29. López-Manchado MA, Biagitti J, Kenny JM. Comparative study of the effects of different fibres on the processing and properties of ternary composites based on PP-EPDM blends. Polym Compos. 2002;23:779-89.

30. Saba N, Jawaid M, Alothman OY, Tahir PM. A review on dynamic mechanical properties of natural fibre reinforced polymer composites. Constr Build Mater. 2016;106:149-59.

31. Corcione CE, Frigione M. Review: characterization of nanocomposites by thermal analysis. Materials. 2012;5:2960-80.

32. Jayanarayanan K, Thomas S, Joseph K. Effect of blend ratio on the dynamic mechanical and thermal degradation behavior of polymer-polymer composites from low density polyethylene and polyethylene terephthalate. Iranian Polymer Journal. 2016;25(4):373-84. 